\title{
Desenvolvimento de Pasteuria penetrans em Meloidogyne spp. Parasitando Diferentes Espécies Vegetais*
}

\author{
Adriana K. Rodrigues ${ }^{1}$, Leandro G. Freitas ${ }^{1}$, Aristéa A. Azevedo ${ }^{2} \&$ Silamar Ferraz $^{1}$ \\ ${ }^{1}$ Departamento de Fitopatologia, Universidade Federal de Viçosa, CEP 36571-000, Viçosa, MG, tel (031) 3899-2925, \\ e-mails: akister@universiabrasil.net, leandro@ufv.br, silamar@ufv.br; ${ }^{2}$ Departamento de Biologia Vegetal, Universidade \\ Federal de Viçosa, CEP 36571-000, Viçosa, MG, tel. (031)3899-2520, e-mail: aazevedo@ufv.br
}

(Aceito para publicação em 07/02/2003)

Autor para correspondência: Adriana Kister Rodrigues

RODRIGUES, A.K., FREITAS, L.G., AZEVEDO, A.A. \& FERRAZ, S. Desenvolvimento de Pasteuria penetrans em Meloidogyne spp. parasitando diferentes espécies vegetais. Fitopatologia Brasileira 28:267-272. 2003.

\section{RESUMO}

A bactéria Pasteuria penetrans é um parasita obrigatório do nematóide das galhas (Meloidogyne spp.) e produz esporos que persistem por anos no solo. A sua produção por cultivo in vitro ainda é inviável e a produção de inoculo requer o seu cultivo in vivo em nematóides parasitando plantas em vasos. Neste trabalho, buscou-se, por meio do estudo histológico de raízes, averiguar diferenças no desenvolvimento de P. penetrans em Meloidogyne spp. parasitando raízes de tomateiro (Lycopersicon esculentum), maxixe (Cucumis anguria) e camapu (Physalis angulata), e possíveis razões para estas diferenças, como forma e tamanho de células gigantes e das fêmeas do nematóide. $\mathrm{O}$ maxixe foi o pior dentre os hospedeiros em teste para a produção de inóculo e apresentou células gigantes anormais. A estrutura das células gigantes assim como o desenvolvimento da bactéria foram semelhantes no camapu e no tomateiro, entretanto o ciclo de vida de $P$. penetrans foi ligeiramente mais curto no tomateiro.

Palavras-chave adicionais: Meloidogyne javanica, $M$. incognita, controle biológico, bactéria, plantas hospedeiras.

\section{ABSTRACT}

Development of Pasteuria penetrans in Meloidogyne spp. parasitizing different host plants

The bacterium Pasteuria penetrans is an obligate parasite of root-knot nematodes and produces spores that persist in soil for many years. At present, in vitro cultivation is not feasible, thereby requiring inoculum production in vivo cultivation, inside nematode parasitizing potted plants. In this work, the differences in the development of $P$. penetrans in Meloidogyne spp. parasitizing roots of tomato (Lycopersicon esculentum), gherkin (Cucumis anguria) and "camapu" (Physalis angulata) were evaluated by histopathology of infected roots. Possible reasons for the differences found were analyzed, such as change in the giant cells or nematode females. The gherkin was the worst host for inoculum production and presented abnormal giant cells. The anatomy of giant cells and the bacterium development were similar in tomato and "camapu" root systems, but the P. penetrans life cicle was slightly shorter in tomato than in camapu.

\section{INTRODUÇÃO}

As perdas na produtividade agrícola atribuídas a nematóides são estimadas em cerca de 100 bilhões de dólares anualmente (Sasser \& Freckman, 1987). Medidas de controle destes nematóides, como variedades resistentes e aplicação de nematicidas, ainda são pouco eficientes. Vários nematicidas já foram retirados do mercado devido aos efeitos nocivos ao ecossistema, à persistência no solo e à contaminação do lençol freático. Esforços têm sido concentrados na integração de agentes de controle biológico e outras estratégias de controle de nematóides (Jatala, 1985).

Pasteuria penetrans (Thorne) Sayre \& Starr é um parasita obrigatório do nematóide das galhas (Meloidogyne spp.), que previne a produção de ovos e impede a penetração dos juvenis nas raízes. Os esporos desta bactéria são muito

\footnotetext{
* Parte da Tese de Mestrado do primeiro autor. Universidade Federal de Viçosa. (2001).
}

resistentes às intempéries e persistem por anos no solo. Entretanto, sua produção por cultivo in vitro ainda é inviável (Williams et al., 1989) e a produção de inóculo requer seu cultivo, in vivo, em nematóides parasitando plantas em vasos (Stirling \& Wachtel, 1980).

Para ocorrer o parasitismo é necessário a adesão dos esporos de $P$. penetrans à cutícula dos juvenis de segundo estádio (J2) de Meloidogyne spp. Quando o esporo está maduro e envolto pelo esporângio (fase IV), a adesão é prejudicada e pode reduzir a eficiência do inóculo bacteriano (O’Brien, 1980; Stirling et al, 1986). Algumas técnicas podem ser utilizadas para o rompimento do esporângio, como o tratamento em ultra-som (Stirling et al., 1986), ou incubação em água destilada (O’Brien, 1980), tornando os esporos livres do esporângio (fase V) e aptos à adesão. Entretanto, a obtenção de esporos sem esporângios, o que ocorre no final do ciclo da bactéria, talvez possa ocorrer em menor período de tempo numa espécie vegetal que permita maior multiplicação do nematóide das galhas. Diferenças na duração do ciclo de vida de $P$. 
penetrans em Meloidogyne javanica (Treub) Chitwood parasitando diferentes hospedeiros já foram observadas. $\mathrm{O}$ maxixe (Cucumis anguria L.) foi um mau hospedeiro e o tomateiro (Lycopersicon esculentum Mill) e o camapu (Physalis angulata L.) se comportaram como bons hospedeiros de $M$. javanica parasitado por P. penetrans (Gomes et al., 1999).

O presente trabalho teve como objetivo a observação do desenvolvimento de $P$. penetrans em $M$. javanica e em $M$. incognita (Kofoid \& White) Chitwood em populações puras, ou em população mista de ambas, em diferentes espécies de plantas hospedeiras, do sítio de alimentação induzido pelos nematóides e da relação destes fatores com a produção e desenvolvimento de esporos de $P$. penetrans.

\section{MATERIAL E MÉTODOS}

Efeito da espécie de Meloidogyne spp. e da planta hospedeira na maturação de Pasteuria penetrans

Foram utilizadas as espécies $M$. javanica $e$. incognita, multiplicadas separadamente em tomateiros em casa de vegetação, e os hospedeiros tomateiro (grupo Santa Cruz), maxixe e camapu. Dentre estas plantas, o tomateiro foi escolhido como hospedeiro-padrão dos nematóides, pois já é utilizado para a multiplicação in vivo de $P$. penetrans (Stirling \& Wachtel, 1980), o maxixe foi usado como mau hospedeiro e o camapu como bom hospedeiro alternativo ao tomateiro. As três espécies vegetais foram semeadas em copos plásticos de $500 \mathrm{ml}$ com mistura solo e areia (1:2), previamente desinfestadas com brometo de metila. Foi utilizado um isolado de P. penetrans (P25), que apesar de ter sido obtido de fêmeas de $M$. arenaria (Neal) Chitwood raça 1, multiplicase bem em M. javanica e M. incognita. Este isolado foi multiplicado e mantido em casa de vegetação do Departamento de Fitopatologia da Universidade Federal de Viçosa, parasitando M. javanica, em tomateiro do grupo Santa Cruz. Esporos de P. penetrans foram obtidos a partir de fêmeas retiradas inteiras de dentro de galhas de raízes e posteriormente esmagadas em água destilada. Os esporos em suspensão foram submetidos ao ultra-som (Stirling et al., 1986) em um processador ultrassônico Cole Parmer® de 70-watts, para promover o rompimento do esporângio e facilitar a adesão ao nematóide. A adesão dos esporos aos $\mathrm{J} 2$ foi realizada em agitador orbital, até que cerca de $80 \%$ dos juvenis apresentassem de cinco a 15 esporos aderidos a cutícula (Giannakou et al., 1999). Plantas de tomateiro, maxixe e camapu com cerca de $10 \mathrm{~cm}$ de altura, foram inoculadas com uma suspensão de nematóides e bactérias, na proporção de $800 \mathrm{~J} 2 /$ planta, depositada em quatro orifícios no solo, ao redor da planta. Os tratamentos se constituíram de inoculação de cada planta hospedeira com as espécies $M$. incognita (Mi) e $M$. javanica (Mj) separadamente, e com a mistura das duas espécies em igual proporção $(\mathrm{Mj}+\mathrm{Mi})$. As plantas foram mantidas em câmara de crescimento a $26^{\circ} \mathrm{C}$ para prolongar o ciclo da bactéria, sendo irrigadas e adubadas com macro e micronutrientes.

Aos 67 dias após a inoculação, foi avaliado o percentual de esporos em cada uma das cinco fases do ciclo da bactéria.
Para tanto, porções de raízes com galhas foram destacadas ao acaso do sistema radicular. Destas galhas, retiraram-se, com estilete metálico, fêmeas do nematóide infetadas pela bactéria. Em cada amostra coletada, dez fêmeas infetadas tiveram seu conteúdo classificado, com relação aos estádios de vida predominantes da bactéria em questão. As fêmeas foram montadas em lactofenol contendo azul de algodão, e esmagadas ao se pressionar a lamínula sobre a lâmina de microscopia. A determinação dos estádios de desenvolvimento de $P$. penetrans foi feita de acordo com Sayre \& Starr (1985), Hatz \& Dickson (1992), Chen et al. (1997) e Serracin et al. (1997). Para a classificação em fases considerou-se o estádio predominante, isto é, quando mais de $50 \%$ das estruturas bacterianas no interior de cada nematóide estivesse em uma das seguintes fases: I) estádio vegetativo inicial - colônias com formas esféricas e sem engrossamento das extremidades do micélio; II) estádio de diferenciação - engrossamento das extremidades do micélio e fragmentação das colônias; III) estádio de esporulação - extremidades do micélio dilatadas se destacando das colônias e se apresentando em forma de losango; IV) estádio de maturação - esporos elipsóides livres e com parede esporangial claramente visível; V) estádio de esporo maduro - esporo completamente formado e livre do esporângio. Os estádios de vida foram determinados, mediante o exame do conteúdo do corpo do nematóide, ao microscópio óptico.

\section{Ciclo de vida de $P$. penetrans em diferentes espécies hospedeiras de Meloidogyne spp.}

Neste ensaio foi usada uma população mista, de $\mathrm{J} 2$, de $M$. incognita e $M$. javanica, de aproximadamente $50 \%$ de cada espécie, multiplicadas em tomateiros em casa de vegetação. Tomateiro, maxixe e camapu foram escolhidos para verificar possíveis diferenças no desenvolvimento de $P$. penetrans parasitando Meloidogyne spp. O semeio das plantas e sua condução, o preparo das suspensões de $P$. penetrans e de Meloidogyne spp. e sua inoculação foram feitos conforme descrito no experimento anterior, sendo utilizado o mesmo isolado de $P$. penetrans.

A partir dos 25 dias após a inoculação (DAI), foram avaliados os estádios de desenvolvimento de $P$. penetrans conforme descrito no experimento anterior, durante 12 semanas.

Porções com galhas foram retiradas das raízes, lavadas em água, fixadas, e desidratadas em série etílico-butílica. Amostras foram incluídas em parafina usando álcool butílico terciário na etapa de infiltração. Os cortes transversais de raízes, com $12 \mu \mathrm{m}$ de espessura, foram colorados, conforme a técnica de coloração quádrupla-triarca proposta por Hagquist (1974), (Rodrigues, 2001).

\section{RESULTADOS}

\section{Efeito da espécie de Meloidogyne e da planta hospedeira na maturação de $P$. penetrans}

Considerando o efeito da espécie de Meloidogyne no desenvolvimento da bactéria, observou-se que esporos de $P$. 
penetrans produzidos em $M$. incognita parasitando plantas de maxixe, se encontravam predominantemente maduros e envoltos pelo esporângio (fase IV), e cerca de $10 \%$ dos esporos estavam sem o esporângio (fase V). Nas plantas de maxixe inoculadas com $\mathrm{Mj}+\mathrm{Mi}, 70 \%$ dos esporos de $P$. penetrans apresentavam-se na fase IV. E nas plantas inoculadas com M. javanica também apresentaram esporos predominantemente na fase IV (70\%), aqueles na fase V eram de aproximadamente $10 \%$ (Figura 1A).

No tomateiro com $\mathrm{Mi}, 70 \%$ dos esporos estavam na fase IV, e aproximadamente $25 \%$ dos esporos estavam na fase V. Em inoculações com Mj $+\mathrm{Mi}, 80 \%$ dos esporos estavam na fase IV e o restante nas demais fases. O desenvolvimento mais rápido e homogêneo da bactéria ocorreu nas plantas inoculadas com $\mathrm{Mj}$, apresentando fase $\mathrm{V}$ predominante $(60 \%)$, e cerca de $30 \%$ na fase IV (Figura 1B).

Em camapu, as plantas que foram inoculadas com $\mathrm{Mj}$ apresentaram esporos predominantemente na fase IV (80\%). Em plantas inoculadas com $\mathrm{Mj}+\mathrm{Mi}$, a fase IV predominou (60\%) e observaram-se muitos esporos na fase V, as fases II e III não foram observadas neste tratamento. Plantas inoculadas com Mi obtiveram 55\% dos esporos na fase IV, e aproximadamente $40 \%$ na fase V (Figura 1C).

\section{Ciclo de vida de $P$. penetrans em diferentes espécies hospedeiras de Meloidogyne spp.}

No $25^{\circ}$ DAI, os três hospedeiros apresentaram a bactéria $P$. penetrans na fase I de desenvolvimento, isto é, em estádio vegetativo inicial. A partir dos $60 \mathrm{DAI}$, nos três hospedeiros havia esporos nas fases iniciais II e III, e fase IV predominante, permanecendo assim até os $81 \mathrm{DAI}$, quando se observou a ocorrência de esporos na fase V. Dos 88 aos 102 DAI, a fase IV predominava, porém, aumentou a ocorrência de esporos na fase V, e as fases iniciais II e III diminuíram. No maxixe não foi possível coletar fêmeas de nematóides aos 102 DAI, pois as plantas estavam no final do ciclo e o sistema radicular apodrecera. Neste hospedeiro, ocorreram poucos esporos maduros, e esporos nas fases iniciais (II e III), foram observados aos 95 DAI (Figura 2A). No tomateiro e no camapu, foram observados maior quantidade de esporos na fase V aos 102 DAI (Figuras 2B e C).

Nos cortes histológicos, foi observado o formato das células gigantes induzidas pelo nematóide nas diferentes hospedeiras. O protoplasma apresentou-se granuloso e pouco denso, com grandes vacúolos e número variado de núcleos hipertrofiados e de formatos irregulares, dispersos nas células gigantes, dependendo do hospedeiro, conforme Huang (1985), Fawole (1988), Starr (1993) e Pedrosa et al. (1996). As paredes das células gigantes apresentaram-se coloridas pelo "fast-green", que tem mais afinidade por paredes celulósicas. Em plantas de tomate, foi normal o aspecto das células gigantes, como descreveu Fawole (1988) e Starr (1993), isto é, de aspecto uniforme, geralmente em número de quatro a sete células por fêmea de nematóide, e vários núcleos hipertrofiados, dispersos no citoplasma. No camapu, as células gigantes apresentaram aspecto normal, bem similar ao que se observou no tomateiro.
Estas se apresentaram uniformes e com delimitações de paredes bem definidas, e em número de quatro a sete células por nematóide. Nas plantas de maxixe, as células gigantes observadas se encontravam deformadas e irregulares, as paredes pareciam dissociadas, e possuíam vários núcleos de formato irregular e agrupados, não sendo possível determinar o número de células por nematóide.

\section{DISCUSSÃO}

\section{Efeito da espécie de Meloidogyne e da planta hospedeira na maturação de $P$. penetrans}

De acordo com Garate et al. (1991) e Blok et al. (1997), que utilizaram métodos moleculares para analisar a similaridade entre as espécies mais comuns de Meloidogyne, $M$. javanica e $M$. arenaria são mais próximas geneticamente entre si do que $M$. incognita e $M$. arenaria. Como o isolado de $P$. penetrans utilizado neste estudo foi originalmente obtido de $M$. arenaria, seu desenvolvimento em $M$. javanica talvez seja consequiência do maior parentesco entre estas duas espécies de nematóides. Além disto, este isolado vem sendo multiplicado em casa de vegetação parasitando $M$. javanica em tomateiros, o que pode ter levado a uma adaptação a este
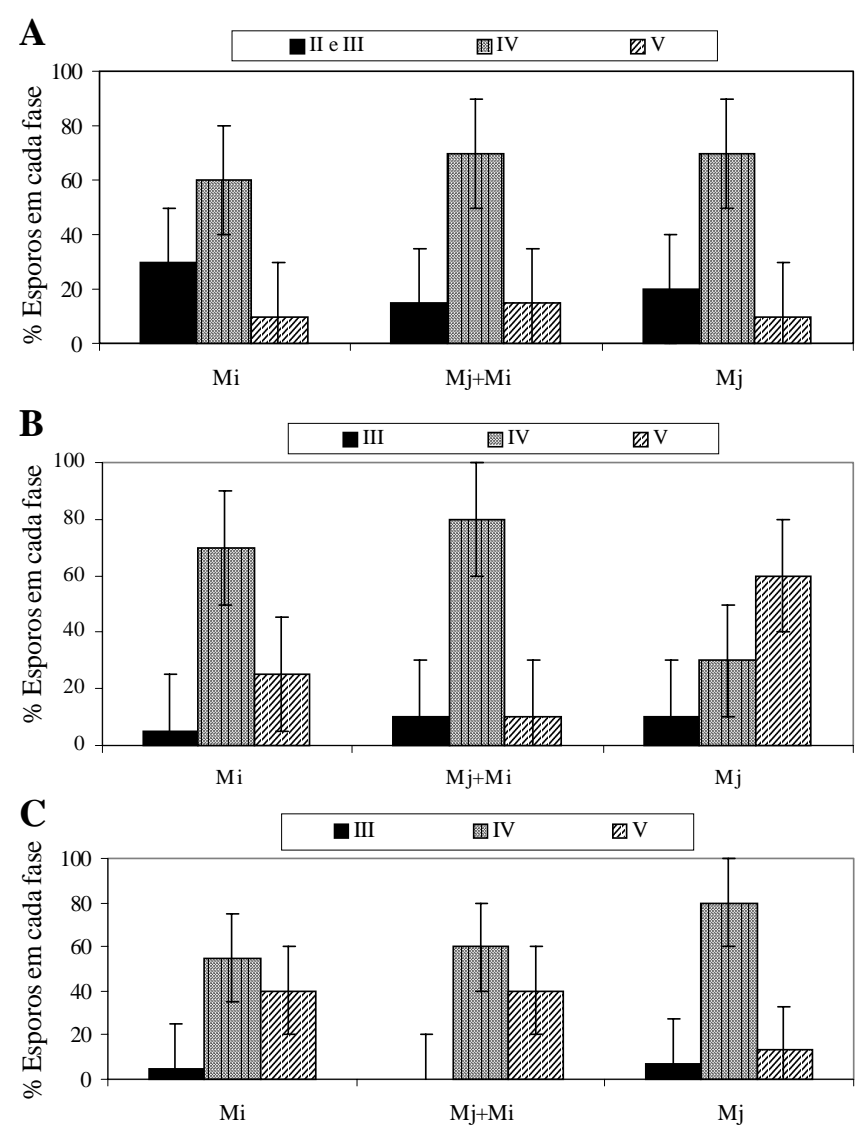

FIG. 1 - Diferentes fases de desenvolvimento de Pasteuria penetrans em Meloidogyne incognita e M. javanica, em população pura e mista, parasitando: A) Cucumis anguria, B) Lycopersicon esculentum, e C) Physalis angulata a $26^{\circ} \mathrm{C}$ após 67 dias da inoculação. 
hospedeiro, como indicam Davies et al. (1994). Este fato confirma os resultados obtidos nas plantas de tomateiro, inoculadas com $M$. javanica, que apresentaram maior freqüência de esporos maduros.

Desconhece-se o nível de suscetibilidade de camapu a $M$. incognita e $M$. javanica, mas como o bom desenvolvimento de $P$. penetrans depende do bom desenvolvimento do nematóide na planta hospedeira, infere-se que talvez o camapu seja melhor hospedeiro de M. incognita do que de M. javanica, pois se observou maior homogeneidade de fases de desenvolvimento nos esporos em Mi. No entanto, são necessários mais estudos para comprovar esta hipótese, e tornar possível o uso desta planta para multiplicação da bactéria em casa de vegetação, pois uma das vantagens para o seu cultivo é a menor incidência de doenças que no tomateiro.
No maxixe, o desenvolvimento mais rápido e homogêneo de $P$. penetrans ocorreu em plantas inoculadas com população mista de $\mathrm{Mj}+\mathrm{Mi}$, onde se observou a predominância de esporos na fase IV. Entretanto, esporos imaturos (fases II e III) foram observados.

Os resultados mostraram que o desenvolvimento de $P$. penetrans foi semelhante nas duas espécies de nematóides, que apresentaram predominantemente esporos maduros, porém envoltos pelo esporângio. Esta semelhança no desenvolvimento é um indício de que, o isolado usado não apresentando elevada especificidade, aderiu-se e desenvolveuse bem nas duas espécies de Meloidogyne. Tal fato está em concordância com Dickson et al. (1994), que relatam que isolados de $P$. penetrans podem aderir-se a diferentes populações, espécies e até mesmo gêneros de nematóides.

A

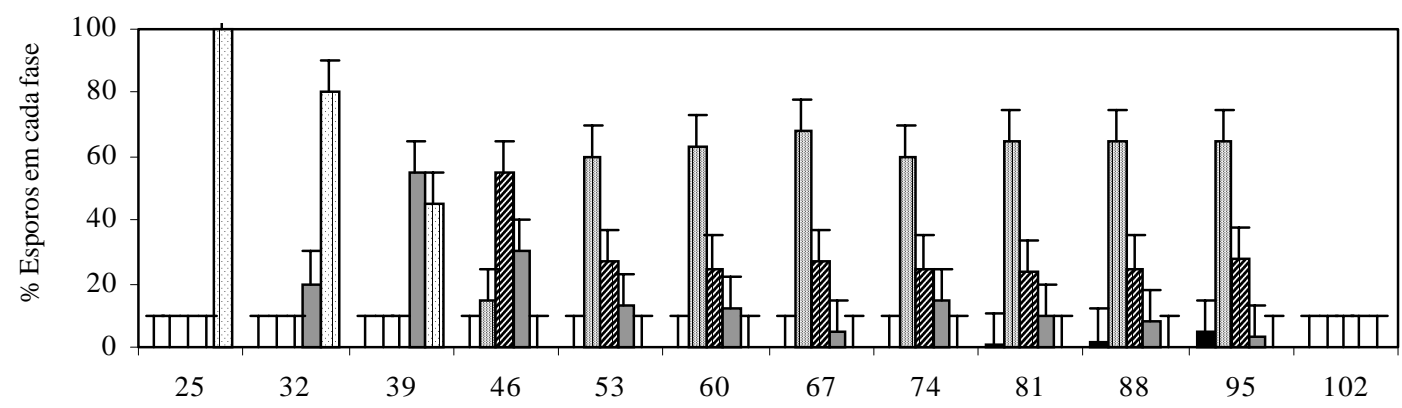

B

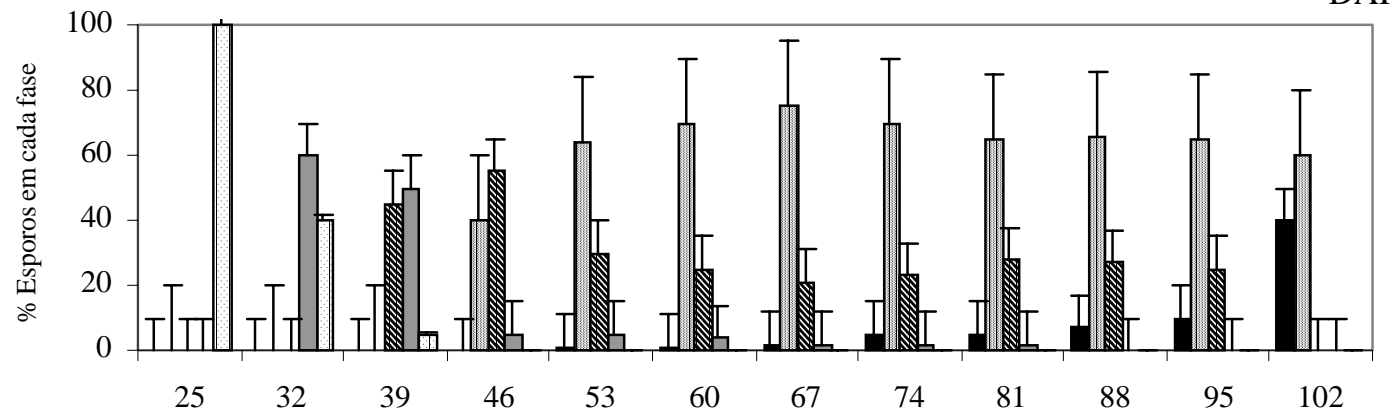

C

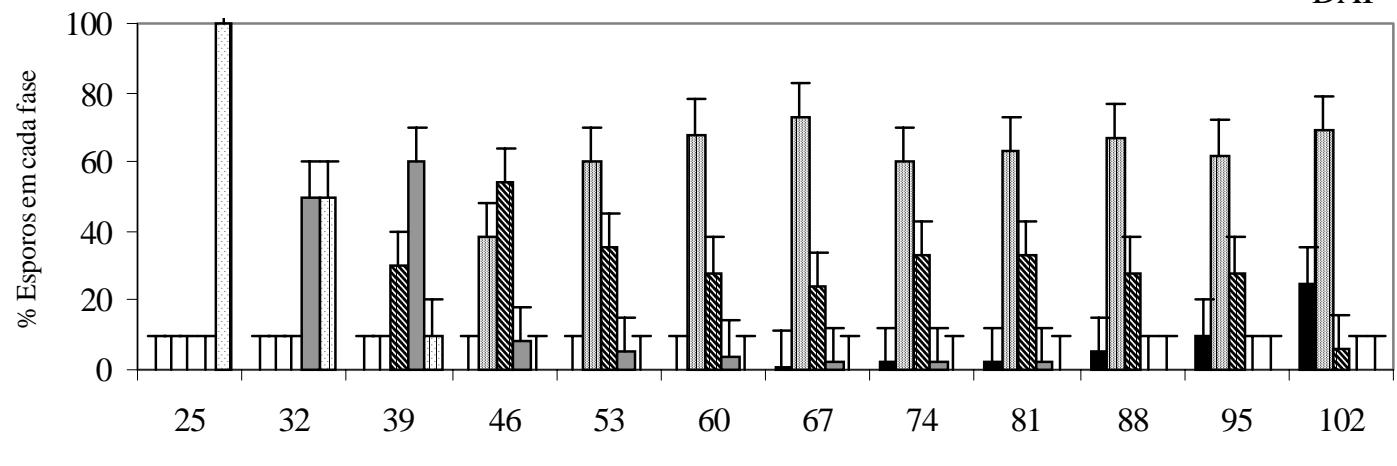

$\square \mathrm{V} \square \mathrm{IV} \mathbb{\mathrm { III }} \square \mathrm{II} \square \mathrm{I}$

FIG. 2 - Médias das porcentagens de esporos ocorrendo nos diferentes estádios de desenvolvimento de Pasteuria penetrans em Meloidogyne spp. parasitando plantas de:A) Cucumis anguria, B) Lycopersicon esculentum e C) Physalis angulata, a $26{ }^{\circ} \mathrm{C}$ dos 25 aos 102 dias após a inoculação (DAI) 


\section{Ciclo de vida de $P$. penetrans em diferentes espécies hospedeiras de Meloidogyne spp.}

A partir das observações descritas, pode-se dizer que, o pior hospedeiro para a produção de $P$. penetrans foi o maxixe, em que quase não havia esporos na fase $\mathrm{V}$, além de serem observados muitos esporos em fases iniciais no final do ciclo da cultura (Figura 2A). Os melhores hospedeiros para produção da bactéria foram o tomateiro, pela quantidade de esporos na fase $V$ no final do ciclo (Figura 2B), e o camapu, pois apresentou predomínio da fase IV e esporos na fase $\mathrm{V}$ (Figura 2C). O desenvolvimento de P. penetrans neste trabalho foi mais lento do que se encontra usualmente na bibliografia (Dickson et al., 1992; Hatz \& Dickson, 1992), pois o experimento foi conduzido em temperatura mais baixa, isto é, $26{ }^{\circ} \mathrm{C}$ ao invés de cerca de $30{ }^{\circ} \mathrm{C}$, para que se pudesse observar melhor as mudanças de fases. O ciclo de vida de $P$. penetrans, foi de 95 dias em maxixe, e de 102 dias em tomateiro e camapu, constatando o que se observou nos trabalhos de Hatz \& Dickson (1992), Chen \& Dickson (1997) e Serracin et al (1997).

Os nematóides induzem a modificação das células do hospedeiro, formando um sítio de alimentação com várias células gigantes multinucleadas (Huang, 1985; Pedrosa et al., 1996). Essas células de alimentação são estruturas altamente especializadas com a função de fornecer nutrientes para o desenvolvimento e reprodução do parasita (Sijmons et al., 1994). São maiores que as células normais da planta, com muitos núcleos, paredes finas e citoplasma denso com muitas organelas. São de alta atividade metabólica, atuando como células de transferência de nutrientes do hospedeiro para o nematóide (Pedrosa, et al., 1996). Através do estudo histopatológico, constatou-se uma relação direta entre o desenvolvimento mais lento da bactéria em maxixe e deformidades no sítio de alimentação do nematóide. Talvez esta seja a explicação para o desenvolvimento de $P$. penetrans nesta hospedeira, confirmando ser uma má hospedeira de nematóide (Gomes et al., 1999), pois, produz poucas galhas e as fêmeas do nematóide são menores. O nematóide induziu a formação de células gigantes deformadas (Figura 3A), e estas talvez sejam ineficientes na metabolização dos fotossintatos da planta hospedeira e transferência destes para o nematóide.

No tomateiro e no camapu, observaram-se melhor desenvolvimento da bactéria, esta preenchendo completamente o corpo do nematóide, e o nematóide associado a sítios normais de alimentação (Figura 3B). Os bons resultados quanto à maturação dos esporos talvez sejam em razão de o nematóide induzir células gigantes bem formadas de alta atividade metabólica (Pedrosa et al., 1996), cujos fotossintatos, talvez, possuam os nutrientes necessários ao bom desenvolvimento da bactéria. O camapu, também uma solanácea, apresentou um bom desenvolvimento da bactéria.

Estes resultados obtidos no desenvolvimento de $P$. penetrans, confirmam o que foi observado no ensaio anterior, onde a má hospedeira de Meloidogyne spp. é também ruim para o desenvolvimento da bactéria. Nas plantas de maxixe, a bactéria desenvolveu-se heterogênea e mais lentamente,

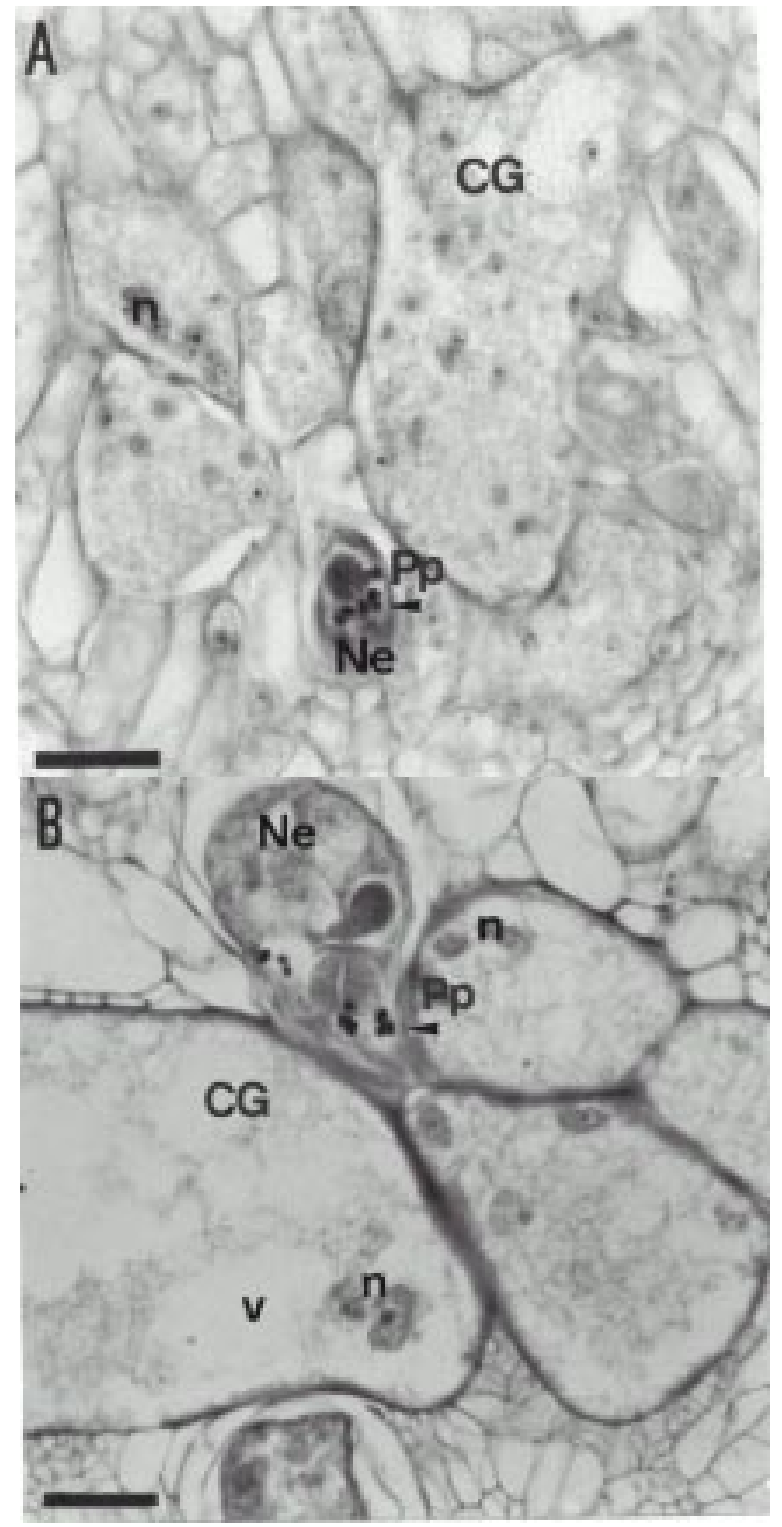

FIG. 3 - A-B. Cortes transversais de raízes com Meloidogyne spp. (Ne) parasitados por Pasteuria penetrans (Pp). A. Cucumis anguria: células gigantes (CG) anormais com protoplasma denso e paredes dissociadas, com vários núcleos (n). B. Lycopersicon esculentum: células gigantes (CG) normais, com vários núcleos (n). Barra $=50 \mu \mathrm{m}$.

apresentando esporos imaturos até a última avaliação. Aqui se observou que as espécies de plantas consideradas como boas hospedeiras para o desenvolvimento de Meloidogyne spp. , o tomateiro e o camapu, apresentam bons resultados na produção e maturação de $P$. penetrans.

\section{REFERÊNCIAS BIBLIOGRÁFICAS}

BLOK, V.C., PHILLIPS, M.S., MCNICOL, J.W. \& FARGETTE, M. Genetic variation in tropical Meloidogyne spp. as shown by RAPDs. Fundamental and Applied Nematology 20:127-133. 1997. CHEN, Z.X. \& DICKSON, D.W. Minimal growth temperature of 
Pasteuria penetrans. Journal of Nematology 29:635-639. 1997.

CHEN, Z.X., DICKSON, D.W., FREITAS, L.G. \& PRESTON, J.F. Ultrastructure, morphology, and sporogenesis of Pasteuria penetrans. Phytopathology 87:273-283. 1997.

DAVIES, K.G., REDDEN, M. \& PEARSON, K. Endospore heterogeneity in Pasteuria penetrans related to adhesion to plantparasitic nematodes. Letters in Applied Microbiology 19:370-373. 1994.

DICKSON, D.W., OOSTENDORP, M. \& MITCHELL, D.J. Development of Pasteuria penetrans on Meloidogyne arenaria race 1 in the field. In: Gommers, F.J. \& Th. Maas, P.W. (Eds.) Nematology from molecule to ecosystem. Dundee. Scotland, European Society of nematologists. 1992. pp.213-218.

DICKSON, D.W., OOSTENDORP, M., GIBLIN-DAVIS, R.M. \& MITCHELL, D.J. Control of plant-parasitic nematodes by biological antagonists. In: Rosen, D., Bennett, F.D. \& Capinera, J.L. (Eds.) Pest management in the subtropics. Biological control:A Florida perspective. Andover. Intercept Ltd. 1994. pp.575-601.

FAWOLE, B. Histopathology of root-knot nematode (Meloidogyne incognita) infection on white yam (Dioscorea rotundata) tubers. Journal of Nematology 20:23-28. 1988.

GARATE, T., ROBINSON, M.P., CHACÓN, M.R. \& R. PARKHOUSE, M.F. Characterization of species and races of the genus Meloidogyne by DNA restriction enzyme analysis. Journal of Nematology 23:414-420. 1991.

GIANNAKOU, I.O., PEMBROKE, B., GOWEN, S.R. \& DOULOUMPAKA, S. Effects of fluctuating temperatures and different host plants on development of Pasteuria penetrans in Meloidogyne javanica. Journal of Nematology 31:312-318. 1999.

GOMES, C.B., FREITAS, L.G. \& TOMÉ. L.G.O. Desenvolvimento de Pasteuria penetrans em diferentes plantas hospedeiras conduzidas em dois tipos de vasos. Fitopatologia Brasileira 24:345. 1999 (Resumo).

HAGQUIST, C.W. Preparation and care of microscope slides. American Biology Teacher 36:414-417. 1974.

HATZ, B. \& DICKSON, D.W. Effect of temperature on attachment, development, and interaction of Pasteuria penetrans on Meloidogyne arenaria. Journal of Nematology 24:512-521. 1992.

HUANG, C.S. Formation, anatomy, and physiology of giant cells induced by root-knot nematodes. In: Sasser, J.N. \& Carter, C.C. (Eds.) An Advanced Treatise on Meloidogyne. vol. I. Biology and control. Raleigh. North Carolina State University Graphics. 1985. pp.155-164.

JATALA, P. Biology control of nematodes. In: Sasser, J.N. \& Carter,
C.C. (Eds.) An Advanced Treatise on Meloidogyne. vol. I. Biology and control. Raleigh. North Carolina State University Graphics. 1985. pp.303- 308.

O'BRIEN, P.C. Studies on parasitism of Meloidogyne javanica by Bacillus penetrans. Journal of Nematology 12:234. 1980 (Abstract).

PEDROSA, E.M.R., HUSSEY, R.S. \& BOERMA, H.R. Cellular responses of resistant and susceptible soybean genotypes infected with Meloidogyne arenaria races 1 and 2. Journal of Nematology 28:225-232. 1996.

RODRIGUES, A.K. Desenvolvimento de Pasteuria penetrans em Meloidogyne spp. parasitando diferentes espécies vegetais. (Tese de Mestrado). Viçosa. Universidade Federal de Viçosa. 2001.

SASSER, J.N. \& FRECKMAN, D.W. A world perspective on nematology:the role of the society. In: Veech, J.A. \& Dickson, D.W. (Eds.) Vistas on Nematology. Maryland. Society of Nematologists. 1987. pp.7-14.

SAYRE, R.M. \& STARR, M.P. Pasteuria penetrans (ex Thorne, 1940) nom. rev., comb. n., sp. n., a mycelial and endospore-forming bacterium parasitic in plant parasitic nematodes. Proceedings of the Helminthological Society of Washington 52:149-165. 1985.

SERRACIN, M., SCHUERGER, A.C., DICKSON, D.W. \& WEINGARTNER, D.P. Temperature-dependent development of Pasteuria penetrans in Meloidogyne arenaria. Journal of Nematology 29:228-238. 1997.

SIJMONS, P.C., ATKINSON, H.J. \& WYSS, U. Parasitic strategies of root-knot nematodes and associate host cell responses. Annual Review of Phytopathology 32:235-259. 1994.

STARR, J.L. Dynamics of the nuclear complement of giant cells induced by Meloidogyne incognita. Journal of Nematology 25:416421. 1993.

STIRLING, G.R. \& WACHTEL, M.F. Mass production of Bacillus penetrans for the biological control of root-knot nematodes. Nematologica 26:308-312. 1980.

STIRLING, G.R., BIRD, A.F. \& CAKURS, A.B. Attachment of Pasteuria penetrans spores to the cuticles of root-knot nematodes. Revue de Nématologie 9:251-260. 1986.

WILLIAMS, A.B., STIRLING, G.R., HAYWARD, A.C. \& PERRY, J. Properties and attempted culture of Pasteuria penetrans, a bacterial parasite of root-knot nematode (Meloidogyne javanica). Journal of Applied Bacteriology 67:145-156. 1989.

WYSS, U., GRUNDLER, F. M.W. \& MUNCH, A. The parasitic behaviour of second-stage of Meloidogyne incognita in roots of Arabidopsis thaliana. Nematologica 38:98-111. 1992. 